\title{
Frequency of Mycoplasma genitalium, Mycoplasma hominis and Ureaplasma urealyticum among Females Patients Attending Gynecology and Obstetrics Clinics at Ain Shams University Hospital
}

\author{
Shimaa A. Abdel Salam ${ }^{1}$ D, Mona A. Khattab ${ }^{1 *}$ (D) and Malames M. Faisal ${ }^{2}$ \\ ${ }^{1}$ Department of Medical Microbiology \& Immunology Faculty of Medicine Ain Shams University, Cairo, Egypt. \\ ${ }^{2}$ Department of Gynecology \& Obstetrics Faculty of Medicine Ain Shams University, Cairo, Egypt.
}

(C) The Author(s) 2020. Open Access. This article is distributed under the terms of the Creative Commons Attribution 4.0 International License which permits unrestricted use, sharing, distribution, and reproduction in any medium, provided you give appropriate credit to the original author(s) and the source, provide a link to the Creative Commons license, and indicate if changes were made. 


\begin{abstract}
Mycoplasmas and Ureaplasmas inhabit the genitourinary tract of sexually active males and females. Mycoplasma genitalium infection as well as Ureaplasma urealyticum are related to many reproductive health problems such as cervicitis, urethritis and pelvic inflammatory disease (PID). the aim of this study was detection of Mycoplasma genitalium, Mycoplasma hominis and Ureaplasma urealyticum cervical colonization among childbearing age females attending Gynecology and Obstetrics clinics at Ain Shams University Hospital by using polymerase chain reaction. This study was conducted on 145 women attending Gynecology and Obstetrics clinics at Ain Shams University Hospital. The patients were divided into three groups according to symptoms. Cervical samples were collected using a sterile swab and placed in a liquid-based transport medium. The detection of Mycoplasma genitalium, Mycoplasma hominis and Ureaplasma urealyticum was performed by using polymerase chain reaction. This study was conducted during the period from January 2018 till August 2018 on145 women attending Gynecology and obstetrics clinic at Ain Shams University Hospital. Ninety females (62\%)were positively colonized with Mycoplasma spp and $U$. urealyticum. M. genitalium was detected in 25 patients ( $28 \%), 10$ patients (11\%) were positive for $M$. hominis and 55 patients (61\%) were positive for $U$. urealyticum. Group (1): 60 patients attending STD clinic. Twenty patients (33.3\%) were positive for $U$. urealyticum, five (8.3\%) were positive for $M$. hominis and seventeen $(28.3 \%)$ were positive for $M$. genitalium. Group (2): 50patientswith premature rupture of membranes. Twenty eight patients $(56 \%)$ were positive for $U$. urealyticum, two patients (4\%) were positive for $M$. hominis and seven patients (14\%) were positive for M. genitalium. Group (3): 35 patients with pelvic inflammatory disease. Seven patients(20\%) were positive for $U$. urealyticum, three patients $(8.6 \%)$ were positive for $M$. hominis and one patient (2.9\%) was positive for $M$. genitalium. The highest prevalence of $U$. urealyticum was associated with premature rupture of membranes. The highest prevalence of $M$. genitalium was determined in STD clinic patients. This study shows a high prevalence of genitourinary infections due to $U$. urealyticum which was considerably higher when compared to Mycoplasma spp. and is significantly associated with premature rupture of membranes. M. genitalium was confirmed as an important cause of STD. The use of PCR for identification of Mycoplasmas and $U$. urealyticum on cervical samples should be recommended. Further studies are needed to definitely associates with Spontaneous rupture of membranes and $U$. urealyticum colonization.
\end{abstract}

Keywords: Mycoplasma genitalium, Mycoplasma hominis, Ureaplasma urealyticum, childbearing age females

\section{INTRODUCTION}

Genus Mycoplasmas and Genus Ureaplasmas are included in class Mollicutes. Different Mycoplasma species ( Mycoplasma hominis, Mycoplasma genitalium) and Ureaplasma urealyticum inhabit the genitourinary tract of many sexually active men and women. The percentage of women with vaginal colonization by Mycoplasma spp, and Ureaplasma spp increases after puberty ${ }^{1}$.

By adulthood, approximately 80 percent of healthy females acquire Ureaplasma spp and up to 50 percent acquire $M$. hominis in their cervical or vaginal secretions ${ }^{2}$.

$M$. hominis and $U$. urealyticum are found frequently in the urogenital tract in both healthy persons and symptomatic patients ${ }^{3}$. M. genitalium is a 'true' pathogen and causes sexually transmitted infection (STI) as urethritis in males. Furthermore, there is increasing evidence that M. genitalium infection is related to adverse outcomes in reproductive health in women, including urethritis, cervicitis, endometritis, pelvic inflammatory disease (PID) and infertility ${ }^{4,5}$.

There is no adequate evidence that $M$. hominis, U. parvum or U. urealyticum, can cause cervicitis, vulvovaginitis, urethritis, PID or infertility, but some studies showed an association between the colonization by one of these microorganisms and a disease condition ${ }^{6,7}$.

However, there is limitation on availability of data regarding Mycoplasmas and Ureaplasmas infections, so studies are needed to understand the contribution of these organisms to unfavorable 
reproductive health outcomes in women and to improve guidelines for both screening and treatment.

\section{Aim of the study}

The aim of the current study is to detect the frequency of $M$. genitalium, $M$. hominis and $U$. urealyticum in child bearing age females attending Gynecology and Obstetrics clinics at Ain Shams University Hospital by using polymerase chain reaction.

\section{PATIENTS \& METHODS}

This study was conducted during the period from January 2018 till August 2018. 145 women attending Gynecology and Obstetrics clinics at Ain Shams University Hospital and fulfilling inclusion criteria were included.

The inclusion criteria were: females in childbearing period (from 20 to 47 years), and complaint of only one of the following: symptoms of vaginitis/cervicitis, (vaginal discharge, pain, itching, burning sensation and dyspareunia), history of premature child delivering or premature rupture of membranes and diagnosis of PID.

Exclusion criteria was administration of antimicrobial therapy within the last 30 days before the evaluation.

\section{Sample collection}

Cervical samples were collected using a sterile swab and placed in a liquid-based transport medium. Informed consent was obtained from patients according to the regulations of Scientific research Ethical Committee Faculty of Medicine Ain Shams University). The samples were stored in -20 until testing.

All cervical samples were subjected to DNA extraction using QIAGEN DNA extraction $\mathrm{Kit}^{\circledR}$ (QIAGEN, USA), for DNA purification according to manufacturer's instructions.

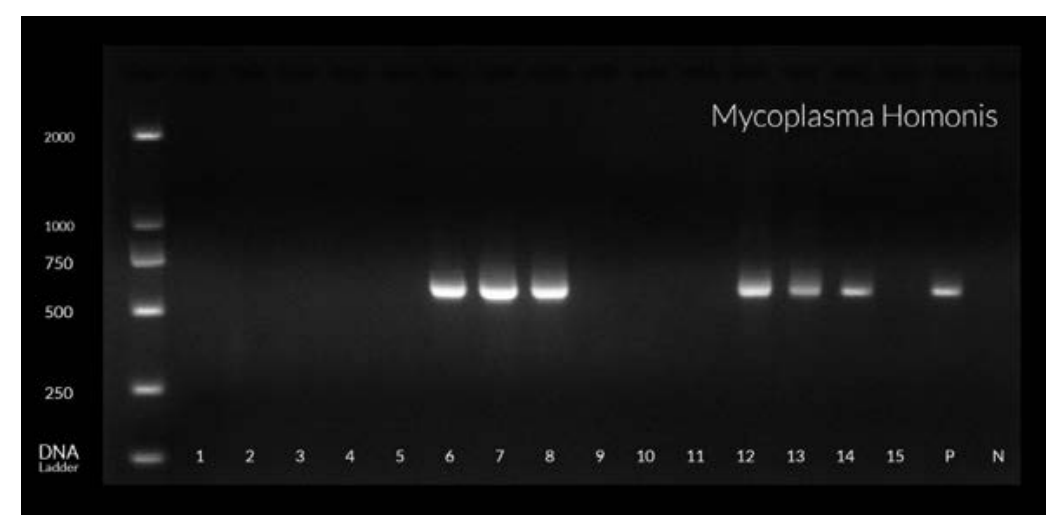

Fig. 1. Gel Electrophoresis of Mycoplasma hominies gene, product size (600) bp

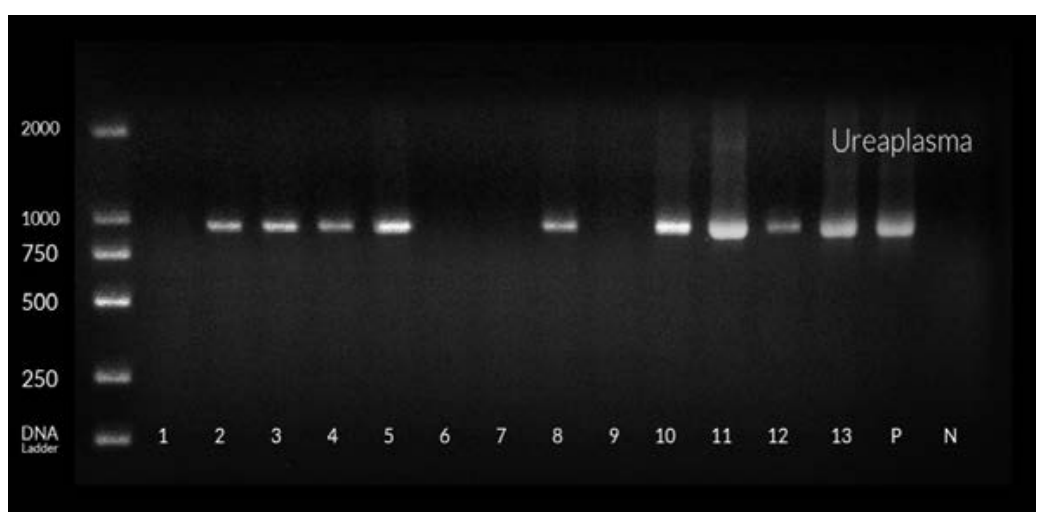

Fig. 2. Gel Electrophoresis of Ureaplasma urealyticum gene, product size (900) bp 


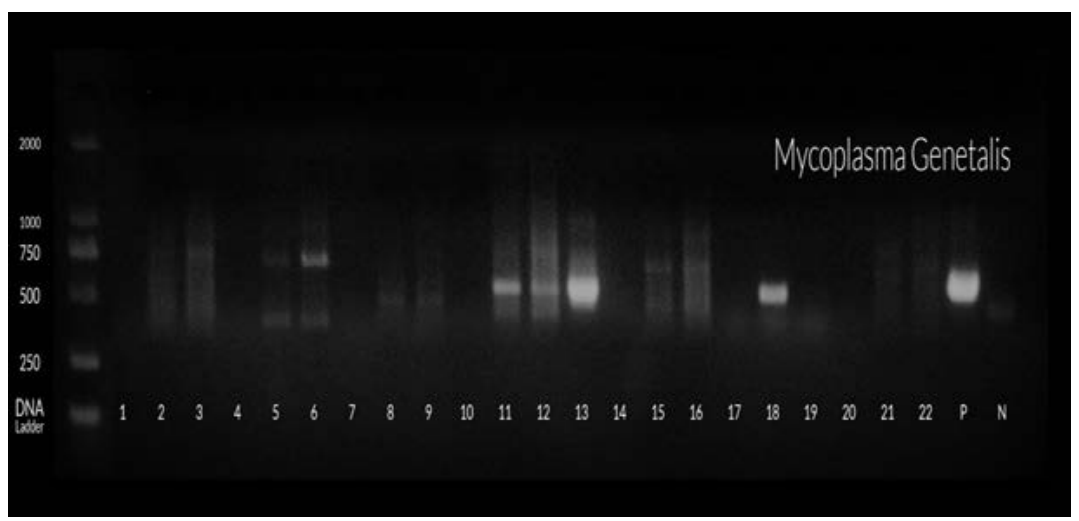

Fig. 3. Gel Electrophoresis of Mycoplasma genitalis gene, product size (500) bp

Amplification of $M$. genitalium, $M$. hominis and $U$. urealyticum genes was done using primers shown in Table (1).

PCR amplification conditions were $95^{\circ} \mathrm{C}$ for $10 \mathrm{~min}$ for denaturation, followed by 35 cycles at $65^{\circ} \mathrm{C}$ for Mycoplasma genitalis, $58^{\circ} \mathrm{C}$ for Ureaplasma urealyticum and Mycoplasma hominis for annealing and a final extension period of 15 $\min$ at $72^{\circ} \mathrm{C}$.

Beta globin was used as internal control, amplification conditions were $95^{\circ} \mathrm{C}$ for $10 \mathrm{~min}$ for denaturation, followed by 35 cycles at $55^{\circ} \mathrm{C}$ for annealing and then final extension at $72^{\circ} \mathrm{C}$ for 15 min. Then the detection of amplified products were done using $2 \%$ agarose gel containing ethidium bromide. Then the products were visualized on a UV transilluminator (365 wavelength). Qiagen gel pilot $250 \mathrm{bp}$ Plus was used as a ladder for molecular weight as shown in Figs (1, 2, and 3).

Data entry and statistical analyses were performed using SPSS (statistical package of social sciences) version 16.0 (SPSS Inc., Chicago, IL, USA).

\section{RESULTS}

This study was conducted on 145 women attending Gynecology and Obstetrics clinics at Ain

Table 1. Primer sequences used in the polymerase chain reaction

\begin{tabular}{llll}
\hline organism & Direction & Primer sequence & Product size \\
\hline Mycoplasma genitalis & MgPa1 & 5' AGT TGA TGA AAC CTT AAC CCC TTG G 3' & \\
& MgPa3 & 5' CCG TTG AGG GGT TTT CCA TTT TTG C 3' & $500 \mathrm{bp}$ \\
Ureaplasma urealyticum & UU AS & 5' ACT ATA TTT CTA TAG CGT CGC AA 3' & \\
& UU S & 5' TCA CCT TAA GTT GGG GAT AA 3' & $900 \mathrm{bp}$ \\
Mycoplasma hominis & Mh s & 5' ACC CAT TGG AAA CAA TGG CTA ATG CCG GAT ACG 3' & $600 \mathrm{bp}$ \\
& MhAs & 5' ATA GAC CCA GTA AGC TGC CTT CGC CT 3' & \\
& B-globin F & 5' TGA GTC TAT GGG ACG CTT GA 3' & $250 \mathrm{bp}$ \\
\hline
\end{tabular}

Table 2. Distribution of the patients in studied groups

\begin{tabular}{lll}
\hline & Groups & Patients N \% \\
\hline \multirow{2}{*}{ Total 145 } & STD Clinic & $60(41.4 \%)$ \\
& Premature rupture & $50(34.5 \%)$ \\
& membrane & \\
PID & $24.1 \%)(35$
\end{tabular}

Table 3. Distribution of Mycoplasma genitalium, Mycoplasma hominis and Ureaplasma urealyticum among total positive colonized patients $n=90$ :

\begin{tabular}{lc}
\hline Detected Pathogen & Total N Positive cases(90) \\
\hline Mycoplasma genitalium & $25(28 \%)$ \\
Mycoplasma hominis & $10(11 \%)$ \\
Ureaplasma urealyticum & $55(61 \%)$
\end{tabular}


Table 4. Distribution of Mycoplasma genitalium, Mycoplasma hominis and Ureaplasma urealyticum among different groups

\begin{tabular}{|c|c|c|c|c|c|c|c|c|c|c|}
\hline & & \multicolumn{9}{|c|}{ Disease group } \\
\hline & & \multicolumn{3}{|c|}{ STD Clinic (60) } & \multicolumn{3}{|c|}{$\begin{array}{l}\text { Premature rupture } \\
\text { membrane (50) }\end{array}$} & \multicolumn{3}{|c|}{$\begin{array}{l}\text { Pelvic inflammatory } \\
\text { disease (35) }\end{array}$} \\
\hline & & $\mathrm{N}$ & $\mathrm{N} \%$ & P-value & $\mathrm{N}$ & $\mathrm{N} \%$ & P-value & $\mathrm{N}$ & $\mathrm{N} \%$ & P-value \\
\hline \multirow[t]{2}{*}{ U. plasma } & Negative & 40 & $66.7 \%$ & $>0.05$ & 22 & $44.0 \%$ & $>0.05$ & 28 & $80.0 \%$ & $\leq 0.05$ \\
\hline & Positive & 20 & $33.3 \%$ & $>0.05$ & 28 & $56.0 \%$ & $\leq 0.05$ & 7 & $20.0 \%$ & $>0.05$ \\
\hline \multirow[t]{2}{*}{ M. hominis } & Negative & 55 & $91.7 \%$ & $>0.05$ & 48 & $96.0 \%$ & $>0.05$ & 32 & $91.4 \%$ & $>0.05$ \\
\hline & Positive & 5 & $8.3 \%$ & $>0.05$ & 2 & $4.0 \%$ & $>0.05$ & 3 & $8.6 \%$ & $>0.05$ \\
\hline \multirow[t]{2}{*}{ M. genitalium } & Negative & 43 & $71.7 \%$ & $>0.05$ & 43 & $86.0 \%$ & $>0.05$ & 34 & $97.1 \%$ & $\leq 0.05$ \\
\hline & Positive & 17 & $28.3 \%$ & $\leq 0.05$ & 7 & $14.0 \%$ & $>0.05$ & 1 & $2.9 \%$ & $>0.05$ \\
\hline $\begin{array}{ll}P>0.05 & \text { Not } s \\
P \leq 0.05 & \text { Highl }\end{array}$ & $\begin{array}{l}\text { cant } \\
\text { nificant }\end{array}$ & & & & & & & & & \\
\hline
\end{tabular}

Shams University Hospital. Their age ranged from 20 to 47.

These patients were divided into three groups according to the clinical presentations as shown in Table 2:

Group (1): Sixty patients(41.4\%) were attending Sexually Transmitted Diseases(STD) clinic with symptoms of vaginitis/cervicitis (mean age $31 \pm 4)$

Group (2): Fifty patients (34.5\%)with diagnosis of premature rupture of membranes (mean age $32 \pm 4$ )

Group (3):Thirty-five patients (24.1\%)with diagnosis of PID (mean age $33 \pm 3$ )

The distribution of $M$. genitalium, $M$. hominis and $U$. urealyticum detection among total positive patients is shown in Table 3. U. urealyticum was the most frequent microorganism detected.

Table 4 shows that in the group (1) there were 20 patients $(33.3 \%)$ positive for $U$. urealyticum, five patients (8.3\%) were positive for M. hominis and seventeen patients (28.3\%) were positive for M. genitalium. A highly statistical association was observed between $M$. genitalium detection and patients attending STD clinic.

In the Group 2, there were 28 patients (56.0\%) positive for $U$. urealyticum, two patients (4.0\%) were positive for $M$. hominis and seven patients (14.0\%) were positive for $M$. genitalium. A highly statistical association was observed between $U$. urealyticum detection and premature rupture of membranes.

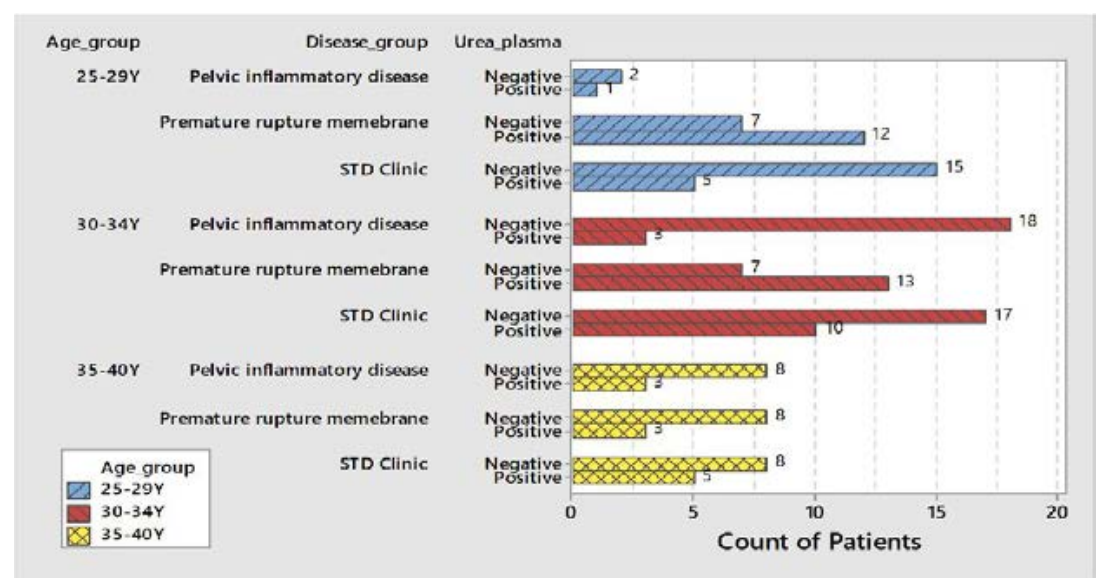

Fig. 4. Distribution of Ureaplasma urealyticum with different age groups and disease group 


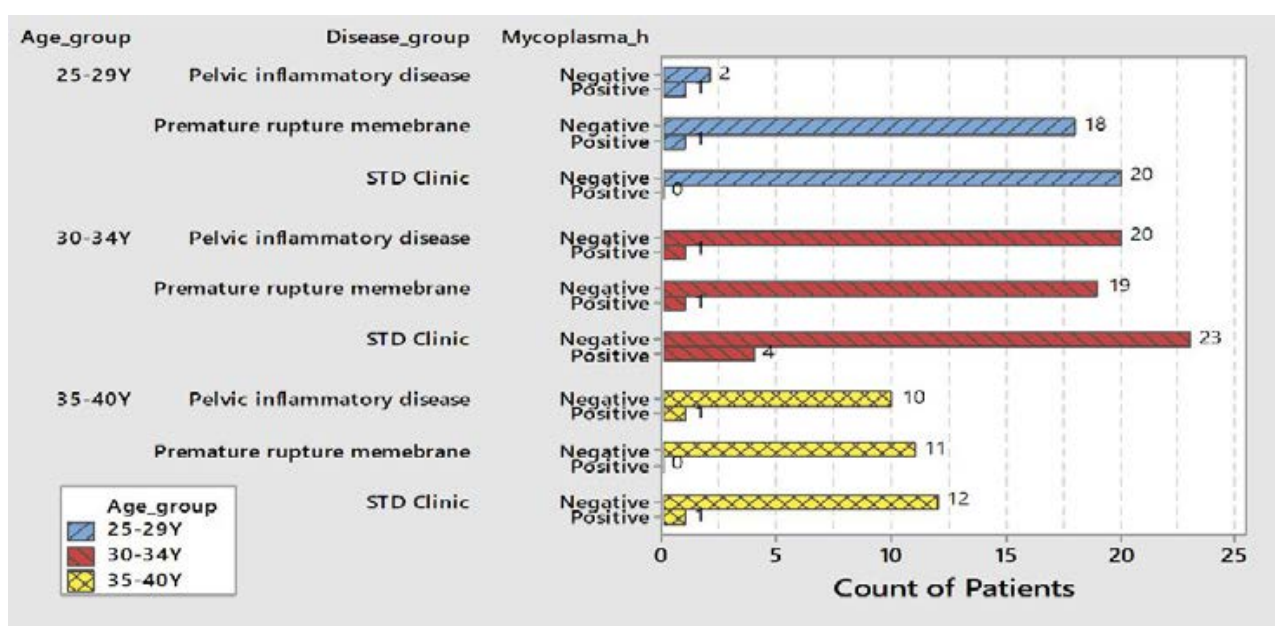

Fig. 5. Distribution of Mycoplasma hominis with different age groups and disease group

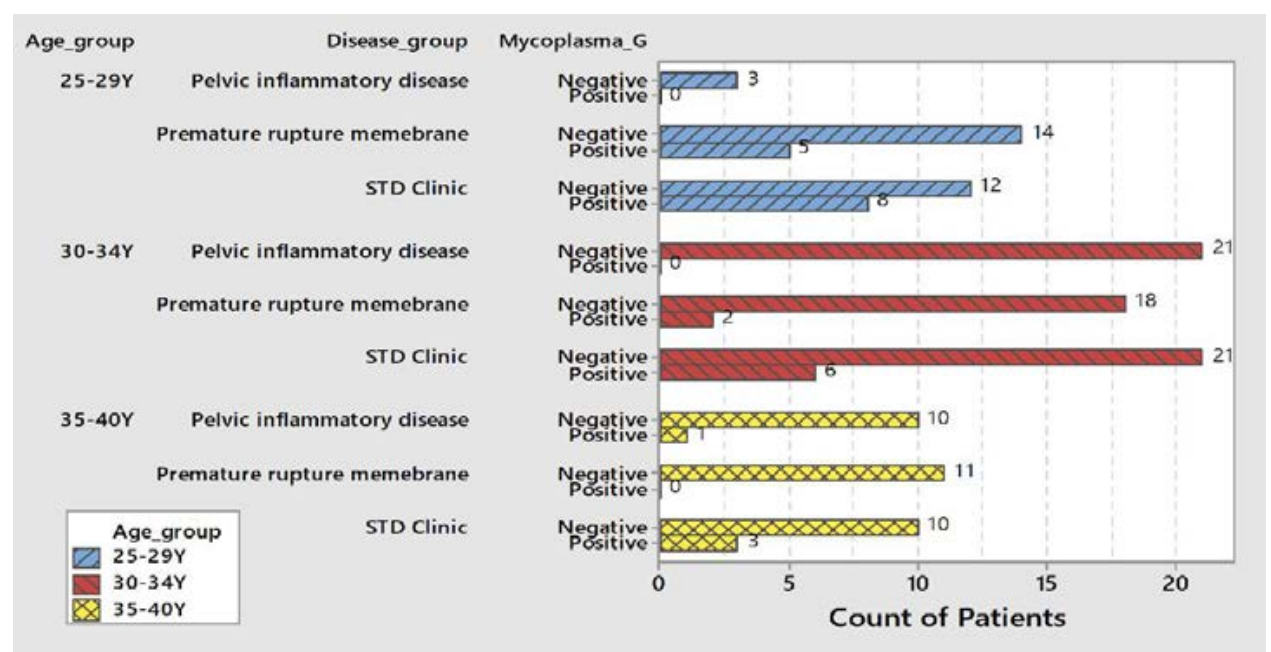

Fig. 6. Distribution of Mycoplasma genitals with different age groups and disease group

In the Group 3, there were seven patients(20.0\%) positive for $U$. urealyticum, three patients $(8.6 \%)$ positive for $M$. hominis and one patient (2.9\%) positive for M. genitalium. No statistical association between diagnosis of PID and M. genitalium, M. hominis and U. urealyticum was observed.

Fig. (4) shows that there was a high prevalence of Ureaplasma urealyticum among patients with premature rupture of membranes especially in the Age group from 25 to 29 years old and age group from 30 to 34 years old.

Fig. (5) shows that the Mycoplasma hominis was highly prevalent among female patients attending STD clinic especially among age group from 30-34 years.
Fig. (6) shows that the high prevalence of Mycoplasma genitals was in patients attending STD clinic especially among age group 25-29 years.

\section{DISCUSSION}

M. hominis and $U$. urealyticum are found frequently in the urogenital tract of humans in both patients and healthy individuals ${ }^{3}$. However, M. genitalium is a 'true' sexually transmitted pathogen causing urethritis in males and there is increasing evidence that $M$. genitalium infection could be related to unfavorable reproductive health outcomes in women, including urethritis, cervicitis, PID, endometritis and infertility and adverse birth outcomes ${ }^{4,5}$. 
The aim of the current study was to detect the distribution of $M$. genitalium, $M$. hominis and $U$. urealyticum in child bearing age females attending Gynecology and Obstetrics clinics at Ain Shams University Hospital by using polymerase chain reaction.

The results of our study showed that out of 145 patients, 90 patients (62\%)were positive for Mycoplasma spp and U. urealyticum. 28\% were positive for $M$. genitalium, $11 \%$ were positive for $M$. hominis and $61 \%$ were positive for $U$. urealyticum. These results are similar to those described by Bayraktar et al. ${ }^{9}$, who reported $U$. urealyticum detection in $44 \%$ of patients and $M$. hominis in $4 \%$ of patients. Moreover, the prevalence of $M$. genitalium was similar to that reported by Balkus et al. ${ }^{4}$

In this study the prevalence of $M$. genitalium was $28 \%$ among studied group, most of cases were detected in age group $\leq 30$ years. Lokken and coworkers reported lower prevalence of Mycoplasma genitalium in Uganda (14\%) and Kenya $(12.9 \%-16 \%)$ than the prevalence in this study ${ }^{10}$. Also, Getman et al., reported prevalence of $M$. genitalium infections in all females (14 to 70 years of age) was $16.3 \%$. M. genitalium infections were significantly more prevalent in subjects $\leq 30$ years of age than in subjects $>30$ years of age ${ }^{11}$. Furthermore, Campos et al. who studied the prevalence of Mycoplasma genitalium and Mycoplasma hominis in urogenital tract of Brazilian women reported that the prevalence of $M$. hominis and $M$. genitalium were detected in $31.8 \%(96 / 302)$ and $28.1 \%(85 / 302)$, respectively and also reported that women under age 25 represent a higher risk for $M$. hominisinfection ${ }^{12}$. As for Mycoplasma hominis infections are found to be less common than Ureaplasma infections. In a study performed by Sarier et al. reported that Mycoplasma hominis infections occur mainly in severely immuno suppressed patients ${ }^{13}$.

Furthermore, patients were divided into three groups: Group (1): patients attending STD clinic, Group (2): patients with diagnosis of Premature rupture of membranes and Group (3): patients with diagnosis of PID.

There was a high prevalence of $U$. urealyticum in the three groups, where it represents $33 \%$ in patients attending STD clinic, $56.5 \%$ in females with premature rupture of membrane and $20 \%$ in PID.

Furthermore, Bayraktar and coworkers reported that there was a high prevalence of $U$. urealyticum among pregnant women in age group18-34 years. They concluded also that $U$. urealyticum was more frequently detected than $M$. hominisin both the controls and patients ${ }^{9}$.

There is an association between the presence of genital mycoplasmas and increased risk of obstetrical complications, such as, preterm labor,spontaneous abortion and delivering low birth weight ${ }^{14}$. Bayraktar and coworkers stated that there is an association between $U$. urealyticum and preterm labor?.

Luton et al. performed a study on 218 pregnant women of different gestational age and followed them. He reported that there is a significant increase in the prevalence of Mycoplasmas as a cervical colonizer during whole pregnancy ${ }^{15}$. Moreover, Lillis et al. reported that 70 women (17.5\%) were positive for M. genitalium among 400 women attending a STD clinic. $M$. genitalium was significantly associated with age $<25$ years $^{16}$.

There are different methods that can be used for detection of Mycoplasmas, like culture, antigen detection, antibody detection and molecular methods. Moreover, the molecular methods allowing simultaneous detection of different species of genital Mycoplasmasis very useful in a clinical setting. Quantitative PCR analysis plays an important role in their diagnosis as it also can show microbial load ${ }^{17,18}$. Furthermore, detection of $U$. urealyticum in culture is difficult so PCR is a gold standard method for its detection. Recent study performed by Sarier et al., they stated that using quantitative PCR in diagnosis of $U$. urealyticum is a valuable test for demonstrating microbial load and avoiding false-positive results. Thus, quantitative PCR analysis plays an important role in the diagnosis since it also can show microbial load ${ }^{18}$.

\section{CONCLUSIONS}

This study shows a high prevalence of $U$. urealyticum and $M$. genitalium in comparison to $M$. hominis as genitourinary infections. There is a significant association between prevalence of $U$. urealyticum and age. U.urealyticum is more prevalent in patients with premature rupture of 
membrane in the current study so there may be an association between $U$. urealyticum infection and obstetrical complications. So testing the presence of Mycoplasma species and $U$. urealyticum during pregnancy may be necessary for better pregnancy outcomes and can be included in the routine follow up of pregnancy. The use of molecular techniques like PCR for identification of Mycoplasma spp and $U$. urealyticum on cervical samples can be beneficial in comparison to culture methods. Further studies are recommended to prove the association between spontaneous abortion and premature rupture of membranes and $U$. urealyticum colonization.

\section{ACKNOWLEDGMENTS}

The authors are grateful to members of obstetrics and gynecology of Ain Shams University hospitals, for their support to carry out this study.

\section{CONFLICT OF INTEREST}

The authors declare that there is no conflict of interest.

\section{AUTHORS' CONTRIBUTION}

All authors designed the study. MMF collected samples from patients. SAAS and MAK performed the molecular work of the study performed PCR on the samples. All authors analyzed the data. All authors wrote the manuscript. All authors read and approved the manuscript.

\section{FUNDING}

None.

\section{ETHICS STATEMENT}

Informed consent was taken from all patients according to the Ethical Committee regulation of Faculty of Medicine Ain Shams University.

\section{DATA AVAILABILITY}

All Datasets generated or analyzed during this study is available.

\section{REFERENCES}

1. Baum SG, Edwards MS. Mycoplasma hominis and Ureaplasma urealyticum infections. Up-ToDate, Waltham, MA. 2017;1-46.
2.

Waites KB, Schelonka RL, Xiao L, Grigsby PL, Novy MJ. Congenital and opportunistic infections: Ureaplasma species and Mycoplasma hominis. In Seminars in Fetal and Neonatal Medicine. 2009;14(4):190-199. WB Saunders. https://doi.org/10.1016/j.siny.2008.11.009

3. Taylor-Robinson D. Mollicutes in vaginal microbiology: Mycoplasma hominis, Ureaplasma urealyticum, Ureaplasma parvum and Mycoplasma genitalium. Res Microbiol. 2017;168:875-881. https://doi. org/10.1016/j.resmic.2017.02.009

4. Balkus JE, Manhart LE, Jensen JS, et al. Mycoplasma genitalium infection in Kenyan and US women. Sexually Transmitted Diseases. 2018;45(8):514-21. https://doi. org/10.1097/OLQ.0000000000000799

5. Unemo M, Jensen JS. Antimicrobial-resistant sexually transmitted infections: gonorrhoea and Mycoplasma genitalium. Nat Rev Urol. 2017;14:139-152. https:// doi.org/10.1038/nrurol.2016.268

6. Kyndel A, Elmer C, Kallman O, Altman D. Mycoplasmataceae colonizationsin women with urethral pain syndrome: a case-control study. J Low Genit Tract Dis. 2016;20:272-274. https://doi. org/10.1097/LGT.0000000000000216

7. Michou IV, Constantoulakis P, Makarounis K, Georgoulias G, Kapetanios V, Tsilivakos V. Molecular investigation of menstrual tissue for the presence of Chlamydia trachomatis, Ureaplasma urealyticum and Mycoplasma hominis collected by women with a history of infertility. J ObstetGynaecol Res. 2014;40:237-242. https://doi.org/10.1111/jog.12165

8. Jensen JS, Uldum SA, Sondergard-Andersen J, Vuust $\mathrm{J}$, Lind K. Polymerase chain reaction for detection of Mycoplasma genitalium in clinical samples. J Clin Microbiol. 1991;29(1):46-50. https://doi.org/10.1128/ JCM.29.1.46-50.1991

9. Bayraktar MR, Ozerol IH, Gucluer N, Celik O. Prevalence and antibiotic susceptibility of Mycoplasma hominis and Ureaplasma urealyticum in pregnant women. Int J Infect Dis. 2010;14(2):e90-5. https://doi. org/10.1016/j.ijid.2009.03.020

10. Lokken EM, Balkus JE, Kiarie J, et al. Association of recent bacterial vaginosis with acquisition of Mycoplasma genitalium. Am J Epidemiol. 2017;186(2):194-201. https://doi.org/10.1093/aje/kwx043

11. Getman D, Jiang A, O'Donnell M, Cohen S. Mycoplasma genitalium prevalence, coinfection, and macrolide antibiotic resistance frequency in a multicenter clinical study cohort in the United States. J Clin Microbiol. 2016;54(9):2278-83. https://doi.org/10.1128/ JCM.01053-16

12. Campos GB, Lobao TN, Selis NN, et al. Prevalence of Mycoplasma genitalium and Mycoplasma hominis in urogenital tract of Brazilian women. BMC Infectious Diseases. 2015;15(1):60. https://doi.org/10.1186/ s12879-015-0792-4

13. Sarier M, Sepin N, Guler $H$, et al. Prevalence of Sexually Transmitted Disease in Asymptomatic Renal Transplant Recipients. Exp Clin Transplant. 2018. https://doi.org/10.6002/ect.2017.0232

14. Clegg A, Passey $M$, Yoannes $M$ and Michael A. High rates of genital Mycoplasma infection in the highlands of Papua New Guinea determined both 
by culture and by a commercial detection kit. J Clin Microbiol. 1997;35:197-200. https://doi.org/10.1128/ JCM.35.1.197-200.1997

15. Luton D, Ville $Y$, Luton-Sigy A, et al. Prevalence and influence of Mycoplasma hominis and Ureaplasma urealyticum in 218 African pregnant women and their infants. Eur J Obstet Gynecol Reprod Biol. 1994;56:95101. https://doi.org/10.1016/0028-2243(94)90263-1

16. Lillis RA, Martin DH, Nsuami MJ. Mycoplasma genitalium infections in women attending a sexually transmitted disease clinic in new orleans. Clin Infect
Dis. 2019;69(3):459-65. https://doi.org/10.1093/cid/ ciy922

17. Bao T, Chen R, Zhang J, et al. Simultaneous detection of Ureaplasma parvum, Ureaplasma urealyticum, Mycoplasma genitalium and Mycoplasma hominis by fluorescence polarization. J Biotechnol. 2010;150(1): 41-43. https://doi.org/10.1016/j.jbiotec.2010.07.024

18. Sarier M, Kukul E. Classification of non-gonococcal urethritis: a review. Int Urol Nephrol., 2019. https:// doi.org/10.1007/s11255-019-02140-2 